\title{
O SENTIDO PRINCIPIOLÓGICO DO TERMO COOPERAÇÃO NO VIGENTE CÓDIGO DE PROCESSO CIVIL
}

\section{THE PRINCIPIOLOGICAL SENSE OF THE TERM COOPERATION IN THE CIVIL PROCESS CODE}

\author{
Jéssica Gonçalves ${ }^{1}$ \\ Luana Soares ${ }^{2}$ \\ Maykon Fagundes Machado ${ }^{3}$
}

1 Doutora em Direito pela Universidade Federal de Santa Catarina (UFSC). Mestra em Direito pela UFSC. Professora do Curso de Direito na Universidade do Vale do Itajaí (UNIVALI). Contato: jessic.goncalves@hotmail.com

2 Estudante de Direito na Universidade do Vale do Itajaí (UNIVALI). Contato: luanasoaress98@hotmail.com

3 Mestrando em Ciência Jurídica pela Universidade do Vale do Itajaí (UNIVALI). Bolsista Fapesc-Univali. Pós-Graduando em Jurisdição Federal pela Escola Superior da Magistratura Federal do Estado de Santa Catarina (ESMAFESC). Graduado em Direito pela UNIVALI (2015-2020). Advogado, inscrito na OAB/SC sob o n. 58.416. Foi Pesquisador Bolsista PIBIC-CNPq, com projeto de pesquisa sob o tema: Governança para a Sustentabilidade Urbana e Regularização Fundiária (2016/2017); e Pesquisador Bolsista ProBIC-UNIVALI, com projeto de pesquisa aprovado sob o tema: Governança Urbana e Sustentabilidade: Análise dos Objetivos do Desenvolvimento Sustentável por meio da Nova Agenda Urbana (2017/2018). Tem experiência na área do Direito, com ênfase em Direito Ambiental, Direito Urbano, Políticas Públicas, Governança Ambiental Global e Sustentabilidade, desenvolvendo pesquisas científicas nesses temas e publicando-as. E-mail: maykonfm2010@hotmail.com 
Resumo: $\mathrm{O}$ artigo discute o sentido jurídico e principiológico do termo cooperação processual no vigente Código de Processo Civil. Para tanto, analisará o Código de Processo Civil do ano de 2015, o qual confere ao magistrado o dever de orientar sua atuação como agente colaborador do processo. O princípio da cooperação processual encontra-se previsto no art. $6^{\circ}$ do Código de Processo Civil e imputa a todos os sujeitos do processo, inclusive ao magistrado, o dever de cooperarem entre si para que se obtenha, em tempo razoável, a decisão de mérito justa e efetiva. Refere-se o termo cooperação tanto ao juiz quanto aos demais sujeitos do processo, mas o magistrado impõe um dever diferenciado, que é o dever de agir como participante ativo do contraditório para que haja celeridade e julgamento adequado. O princípio da cooperação processual reflete a democracia participativa também presente no interior do jogo do processo civil e o pleno e ativo exercício de cidadania.

Palavras-chave: Princípios no Processo Civil. Princípio da coo- peração processual. Magistrado.

Abstract: This article discusses the juridical and theoretical meaning of the term procedural cooperation in the Code of Civil Procedure in force. For this purpose, the Code of Civil Procedure for the year 2015 will be analyzed, which gives the magistrate the duty to guide his action as a collaborating agent of the process. The principle of cooperation is found in article 6 of the Code of Civil Procedure, and it will be seen that all the subjects of the process must cooperate with each other to obtain a fair and effective decision in a reasonable time - thus, it serves both to the judge as to the parties the system of cooperation in the process, it being incumbent upon the judge to act as an active participant of the adversary, so that there is speed and a fair trial. Given all this, this principle defends the need for a participatory democracy in the process, with the most active exercise of citizenship.

Keywords: Principles in Civil Procedure. Principle of procedural cooperation. Magistrate.

\section{INTRODUÇÃO}

Até o ano de 2015, a preferência institucional do Poder Judiciário para tratar os conflitos entre as pessoas dava-se por 
meio da chamada heterocomposição, especificamente a jurisdição pública (o Estado, personificado na pessoa do magistrado, decidindo o caso concreto).

Após uma crise estrutural no interior do Poder Judiciário principalmente de morosidade e litigiosidade - , diversas mudanças legislativas foram feitas, dentre as quais se destacam: Resolução n. 125 do Conselho Nacional de Justiça, Lei no 13.140/15 (Lei da mediação) e Lei 13.105/15 (vigente Código de Processo Civil).

As mencionadas normas mudaram a preferência do Estado em solucionar os conflitos, estimulando a cooperação.

Constata-se que, atualmente, o sistema jurídico brasileiro dá preferência para a autocomposição, sobretudo a abordagem colaborativa, impondo às partes o desafio de consolidarem um consenso entre si.

Partindo desse contexto histórico, o artigo visa discutir o sentido jurídico e principiológico do termo cooperação processual no vigente Código de Processo Civil, em especial a mudança legislativa que inseriu o art. $6^{\circ}$ e a nomenclatura cooperação e suas demais nuances para melhor andamento processual.

Dessa forma, serão analisadas algumas normas fundamentais principiológicas infraconstitucionais, principalmente o sentido do termo cooperação e o seu tratamento notadamente para a figura do juiz ativo e colaborativo para a solução dos problemas, juntamente com a inserção de diversos poderes e deveres.

Ressalte-se que o sistema jurídico inovou ao incluir o princípio da cooperação, que permite, além de maior celeridade, a posição do magistrado em tomar uma decisão que realmente satisfaça as partes.

A técnica de pesquisa utilizada foi a bibliográfica, uma vez que o desenvolvimento da pesquisa se deu por meio de materiais já publicados em livros e artigos científicos. 


\section{MUDANÇAS LEGISLATIVAS E A INCLUSÃO DO TERMO COOPERAÇÃO NO NOVO CÓDIGO DE PROCESSO CIVIL}

Diversas mudanças legislativas foram feitas ao longo da história, dentre as quais se destacam: a Resolução n. 125 do Conselho Nacional de Justiça, a Lei $\mathrm{n}^{\mathrm{o}}$ 13.140/15 (Lei da mediação) e a Lei 13.105/15 (vigente Código de Processo Civil).

As mencionas normas mudaram a preferência do Estado em solucionar os conflitos, estimulando a cooperação.

Assim, um dos nortes para a atuação do Estado como Juiz direciona-se no sentido de que ele deve promover, sempre que possível, a solução consensual. Há uma preferência pelo diálogo entre as próprias partes para que elas alcancem uma solução de modo consensual e não coercitiva.

A solução consensual deve ser a meta do Poder Judiciário, estimulando as partes a firmarem um acordo e determinando a todos os sujeitos do processo também o dever de estimular a cooperação.

O Código de Processo Civil descreve como uma das suas primeiras mudanças o princípio da cooperação, que determina que "todos os sujeitos do processo devem cooperar entre si para que se obtenha, em tempo razoável, decisão de mérito justa e efetiva".

Nessa perspectiva, afirma Fernanda Tartuce (2018, p. 3):

[...] a substituição gradual da mentalidade contenciosa por olhares que contemplam meios extrajudiciais passa, decididamente, pela vivência de experiências proveitosas. Oportunidades existem: diversas iniciativas vêm sendo engendradas no país para que desenlaces produtivos tenham lugar a partir da construção de consensos.

Dessa forma, as partes deverão cooperar entre si, o que torna o art. $6^{\circ}$ do Código Processo Civil muito importante, pois 
faz com que se minimizem as discussões entre as partes, já que ambas necessitam colaborar umas com as outras para que o processo transcorra de maneira célere e eficaz.

Entretanto, não apenas as partes deverão cooperar entre si, mas também todos os sujeitos do processo, incluindo os juízes, que deverão participar ativamente a fim de proferir uma decisão adequada.

Outra mudança que veio à tona no novo Código de Processo Civil em torno também do termo cooperação encontra-se na chamada fase do saneamento do processo, prevista no art. 357 desse Diploma.

Entendendo que no caso ainda estão presentes pontos controvertidos, marca-se uma audiência de saneamento convocando as partes para participarem e colaborarem com o ordenamento compartilhado e a correção de determinados pontos obscuros.

Mais uma questão interligada com a cooperação reside no capítulo próprio das intervenções de terceiro, em especial a figura do amicus curiae (amigo da corte), que passa a ser admitida em qualquer processo com potencial repercussão social e com uma notável demanda repetitiva.

Dessa forma, as decisões repetitivas dos processos servirão de paradigma para as demais ações semelhantes e terão o condão de influenciar na vida de várias pessoas, podendo se utilizar do instituto do "amigo colaborativo", o qual equilibra um possível déficit democrático a fim de dar acesso para a manifestação de determinados grupos.

Tais exemplos demonstram que a colaboração processual no seu sentido jurídico e principiológico impõe uma mudança de paradigma no atual sistema processual: se no Código de Processo Civil do ano de 1973 vigorava a relação jurídica processual triangular entre o juiz e as partes. 
A forma adequada seria manter-se aquele equidistante e alheio a qualquer auxílio processual para se obter a solução justa de mérito no processual. No Código de Processo Civil do ano de 2015, a relação triangularizada cede espaço para a relação angular (equilibrada entre todos), atribuindo-se, no entanto, mais poderes e, por consequência, mais deveres ao juiz.

\section{NORMAS FUNDAMENTAIS PRINCIPIOLÓGICAS INFRACONSTITUCIONAIS}

Estabelece o estudo da hermenêutica que norma é gênero do qual regras e princípios são espécies, não existindo uma diferença hierárquica entre eles (regras e princípios).

A regra não é mais ou menos importante que o princípio e vice-versa. Se as regras e os princípios são espécies de normas, logo os dois - tanto as regras quanto os princípios - são dotados de exigibilidade, podendo o juiz decidir com base em um ou em outro.

A proposta de diferenciação entre ambos reside no fato de que as regras são mais específicas e se prestam a regular mais diretamente o caso concreto, aplicando-se na base do "tudo ou nada" (aplica ou não aplica).

Percebe-se que os princípios são mais vagos e acabam sendo delimitados diante do caso concreto, ou seja, aplicam-se conforme o caso, sendo usados para contemplar a peculiaridade fática.

Dessa forma, investe-se em princípios para que, no exercício da jurisdição, quando o magistrado for solucionar um conflito (dizer um direito), ele consiga observar e adaptar às peculiaridades do caso.

Destaca-se que o Código de Processo Civil trouxe para o plano infraconstitucional diversificadas normas fundamentais para a relação processual, pois diversos princípios são repeti- 
ções dos textos constitucionais; já outros são apenas uma decorrência destes.

Ademais, as normas fundamentais principiológicas vinculam os atores do processo a uma atuação de caráter constitucional, fundamentada num processo com ética, agilidade e compromisso. Assim, serão abordadas algumas das normas fundamentais principiológicas infraconstitucionais que proporcionam uma jurisdição mais justa e coerente.

\subsection{Princípio da inércia (iniciativa) e impulso oficial (desenvolvimento do processo)}

De acordo com o art. $2^{\circ}$ do Código Processo Civil, a iniciativa do processo se dá pela parte e se desenvolve por meio do magistrado (impulso oficial), salvo as exceções previstas em lei.

O princípio de a parte ajuizar a ação e instaurar o processo garante que ninguém será acionado pela vontade do Estado/ Juiz, havendo a necessidade de manifestação pelo outro.

Esse princípio é marcado pelo fato de que o Estado/Juiz fica proibido de iniciar uma demanda judicial em nome da parte, assim nenhum juiz poderá prestar a tutela jurisdicional sem o requerimento da parte.

O processo é um conjunto de iniciativas ao longo do tempo, sob a supervisão e os impulsos do juiz responsável, que, de certa forma, organiza os procedimentos e decide como deve ser seu seguimento.

O autor inicia o processo, mas ambas as partes têm o poder de alterar o objeto do processo. Outra possibilidade é a de o Juiz inserir no polo passivo alguma pessoa "ex officio".

Entretanto, a fixação das partes é dever do autor, indicando a lide e os envolvidos, não cabendo ao juiz realizar isso de ofício, pois é dever das partes indicar contra quem ajuíza 
a ação, nos limites da pretensão posta em juízo, sob pena de inépcia da inicial, sujeição de ver a ilegitimidade da parte ré ou improcedência da ação.

Logo, não cabe ao juiz responsável a correção ao polo passivo da ação judicial, pois a parte autora tem a opção contra quem deseja manejar seus pedidos visto que, se o autor errar, ainda que em caso de litisconsórcio passivo necessário, será extinto o feito, caso não se atenda aos termos do art. 115, parágrafo único, do CPC.

Sabe-se que os órgãos jurisdicionais não devem possuir interesse, devendo, também, ser imparciais, uma vez que são características de sua própria existência.

Destaca-se que, se o juiz tivesse que provocar a tutela jurisdicional, ele teria que fazer providências a ele mesmo, o que não seria acolhido em sede processual.

Elpídio Donizetti (2010, p. 87) aduz que a jurisdição somente agirá quando for provocada por meio de ação e, se instigada, terá de agir por impulso, independentemente de qualquer vontade das partes. Assim, cabe ao magistrado promover a continuidade dos atos processuais até a solução do litígio.

Desse modo, como declarado, a parte autora tem o dever de iniciar o processo e, em seguida, o juiz tem o dever de orientar os demais atos até a decisão final.

\subsection{Princípio da razoável duração do processo}

Vê-se que o tempo de duração razoável do processo não é aquilo que pode ser contabilizado em um relógio, pois cada caso possui a sua peculiaridade.

Note-se que o processo não pode ser rápido demais nem demorado demais, ele possui seu tempo para que a decisão seja justa e de acordo com os fatos e bem fundamentada conforme cada situação. 
Informa-se também que algumas pessoas possuem o direito a tempo de tramitação preferencial por conta de condições especiais e tuteladas, como os idosos, as crianças e os adolescentes.

De acordo com o art. 12 do Código de Processo Civil, para promover a agilidade e a transparência, os juízes e os tribunais terão de seguir a ordem cronológica, preferencialmente de conclusão, para proferir sua sentença ou seu acórdão, ou seja, o juiz poderá ou não seguir essa regra.

O princípio da duração razoável do processo deverá ser aplicado juntamente com os princípios da razoabilidade e da proporcionalidade para que o processo não se estenda além do razoável, bem como não poderá se comprometer com a ampla defesa e o contraditório, o que poderá trazer enormes prejuízos para uma das partes.

Pondera Humberto Theodoro Júnior (2018, v. 1, p. 65-67):

Não há, nem poderia haver, na lei, uma predeterminação do tempo qualificado como razoável para a conclusão de um processo. $\mathrm{O}$ que não se pode tolerar é a procrastinação injustificável decorrente de pouca ou total ineficiência dos serviços judiciários, de modo que a garantia de duração razoável se traduz na marcha do processo sem delongas inexplicáveis e intoleráveis.

O autor Marcelo Lima Guerra (2003, p. 82) informa que a duração razoável do processo depende das medidas judiciais destinadas a garantir sua realização no poder do magistrado, além das medidas ligadas à reparação de danos ocasionados por sua violação.

Alexandre de Moraes (2006, p. 456) afirma que as previsões já estavam contempladas no texto constitucional, tanto no princípio do devido processo legal quanto na previsão do princípio da eficiência. 
Essas organizações somente serão estabelecidas se for concretizado o empenho dos envolvidos em preservar e trabalhar para que a boa-fé prevaleça.

\subsection{Princípio da boa-fé processual objetiva}

A boa-fé objetiva vem de forma obrigatória no art. $5^{\circ}$ do Código de Processo Civil de 2015.

Observa-se que o Código de Processo Civil de 2015 aborda o pedido e igualmente trata da boa-fé objetiva no art. 324, § 20: "A interpretação do pedido considerará o conjunto da postulação e observará o princípio da boa-fé." (BRASIL, 2015).

Vê-se que a boa-fé está interligada à ética. Trata-se do esforço para o cumprimento dos atos jurídicos relevantes no convívio social.

Assim, a boa-fé se manifesta na forma objetiva, qual seja, o estado de consciência da pessoa, em que o intérprete considera a intenção da pessoa em seus aspectos psicológicos e íntimos e também se manifesta de forma objetiva, que está qualificada na conduta de honestidade, lealdade, valorização de interesses do outro.

Quando dito que houve litigância de má-fé, quer dizer que houve a quebra da boa-fé, conforme o Código de Processo Civil de 2015.

Conforme o art. 489, $\S 3^{\circ}$, do Código de Processo Civil, fica demonstrado que a decisão judicial deve ser interpretada a partir da conjugação de todos os seus elementos e em conformidade com o princípio da boa-fé.

Dessa forma, fica explanado que não basta somente a ausência de má-fé no processo, constituindo, como necessária, a boa-fé objetiva. 


\subsection{Princípio da paridade de tratamento ou isonomia processual}

De acordo com o art. $7^{\circ}$ do Código de Processo Civil, a igualdade de tratamento das partes no processo significa o prestígio ao exercício dos direitos e das faculdades processuais propiciado pelo contraditório substancial de forma efetiva.

Essa igualdade deverá ser com relação ao exercício de direitos, meios de defesa, ônus, deveres e também com relação à aplicação de sanções, devendo o juiz interessar-se no âmbito do contraditório.

José Afonso da Silva (2005, p. 223) esclarece que o princípio da igualdade consiste em tratamento igual a situações iguais e tratamento desigual a situações desiguais.

Já Marcus Vinicius Rios Gonçalves (2016, p. 72) aduz que o princípio primeiramente deve orientar o legislador sobre a edição das leis, em que devem dar tratamento igual entre os litigantes e depois deverá nortear os julgamentos, orientando, assim, o juiz sobre a melhor condução do processo.

Vê-se aqui a isonomia como uma paridade, para além da necessidade de se distinguir igualdade de isonomia.

O tratamento das partes de forma a conceder os mesmos acessos que o sistema determina com as mesmas oportunidades e as possibilidades de participação no processo, retirando, nesses casos, as pessoas que têm prioridades no processo, como os idosos, as crianças e os adolescentes.

Diante disso, o magistrado poderá aplicar o direito ao caso concreto, conforme o art. $8^{\circ}$ do Código de Processo Civil, respeitando a dignidade da pessoa humana e os fins sociais da norma. 


\subsection{Fins sociais do processo e bem comum}

Esse princípio trata de orientar o julgador tanto na forma de acompanhar o julgamento quanto na forma de decisão.

Ao julgar o caso, atendendo aos fins sociais do ordenamento jurídico e às exigências do bem comum, o juiz deve resguardar e promover a dignidade por meio da observação da proporcionalidade, da razoabilidade, da legalidade, da publicidade e da eficiência.

Assim, o art. $8^{\circ}$ do Código de Processo Civil determina como atender aos fins sociais e ao bem comum, visto que temas abertos que demandam o preenchimento de seus sentidos por meio da fundamentação completa de cada qual dessas atitudes.

E o art. $1^{\circ}$, III, da Constituição Federal informa que, para atender aos fins sociais e ao bem comum, se deve construir uma sociedade livre, justa e solidária.

\subsection{Princípio do contraditório e da não surpresa}

O princípio do contraditório encontra-se no art. $5^{\circ}, \mathrm{LV}$, da Constituição Federal e decorre do princípio da isonomia, devendo ser substancial.

Nesse princípio, a lei determina que a parte realmente influencie na decisão por meio de sua participação ativa no desenvolvimento do processo.

Nos julgamentos, nem os pedidos nem as provas produzidas são analisadas, fazendo com que esse princípio não se encaixe. Logo, todos os argumentos devem influenciar e ter peso na decisão, devendo ser analisados pelo juiz e acatados ou negados.

Ter um contraditório em que os argumentos das partes são base para a sentença é meramente formal e, atualmente, deve servir de fundamento recursal para a nulidade do julgado. 
O art. 10 do Código de Processo Civil informa que é impossível de se decidir contra alguém que não teve oportunidade de manifestação. Desse modo, havendo negativa de intimação ou falha nos mecanismos de justiça que impeça a parte de participar de cada fase do processo, a formação da decisão será viciada.

Outrossim, o contraditório é uma garantia dinâmica e o núcleo do processo, pois se apresenta como corolário do Estado Democrático de Direito.

\subsection{Princípio da fundamentação das decisões judiciais}

O Estado Democrático de Direito impõe limites à atuação de seus agentes, que devem agir invariavelmente nos limites da Constituição e das normas jurídicas pautadas por ela, sempre de maneira fundamentada técnica e faticamente. Dessa forma, todos os julgamentos dos Órgãos do Poder Judiciário devem ser fundamentados.

O dever de fundamentar dá a garantia que sua decisão não será arbitrária e propicia seu controle por meio de recurso.

A fundamentação das decisões judiciais garante que a lei seja cumprida e que a arbitrariedade do Poder Judiciário seja afastada do processo, fazendo com que o juízo seja imparcial, a fim de evitar o subjetivismo.

Dessa forma, devendo o juízo fundamentar suas decisões, fica garantido que serão sempre tratadas de acordo com a lei, trazendo, assim, grande segurança jurídica aos indivíduos sujeitos à lei.

Além da garantia das partes, salienta-se a função política da motivação dos atos judiciais, cujos destinatários são todas as demais pessoas, pois se afere à imparcialidade do juiz, à legalidade e à justiça das decisões. 
Por fim, destaca-se que, por meio da fundamentação, seria mais fácil fiscalizar e limitar a atuação do magistrado.

Afirma-se, então, que a fundamentação correta e que atende à Constituição e ao Código de Processo Civil traz consigo a segurança jurídica, a imparcialidade e a confiança, deixando claro o motivo da escolha do argumento, individualizando a norma aplicada, explicando e qualificando as alegações de fato, realizando a ligação causal entre fato e norma e esclarecendo os motivos da conclusão.

\subsection{Do princípio da conciliação e dos métodos alternativos de resolução de conflitos}

Importante destacar que o Código de Processo Civil traz consigo o anseio em satisfazer com efetividade a grande problemática implementada no Judiciário, qual seja, o excesso de litigiosidade.

Desse modo, implementa-se no referido Diploma e entende-se que esse se norteia pelo Princípio da Conciliação.

$\mathrm{Na}$ concepção de Lima (2003, p. 6), conciliação trata-se precipuamente de:

[...] um método alternativo de resolução de disputas, em que um terceiro imparcial, denominado conciliador, auxilia as partes envolvidas no conflito na busca de um acordo. Nesta modalidade, pode o conciliador propor soluções para o problema.

Havendo, assim, um terceiro denominado conciliador, auxiliando as partes em conflito, esse inclusive pode propor soluções ao problema em discussão, o que não se confunde com a mediação, por isso a importância do destaque para fins de esclarecer as particularidades de cada mecanismo de resolução de controvérsia.

Aliás, Warat (2001, p. 80) possui observação atenta acerca do mecanismo da conciliação: 
[...] a conciliação não trabalha o conflito, ignora-o, e, portanto, não o transforma. $\mathrm{O}$ conciliador exerce a função de negociador do litígio, reduzindo a relação conflituosa a uma mercadoria. O termo de conciliação é um termo de cedência de um litigante a outro, encerrando-o. Mas, o conflito no relacionamento, na melhor das hipóteses permanece inalterado.

Warat (2001) esclarece de forma sucinta o busílis. Ora, se o conflito em questão não for tratado em sua raiz, acaba-se retornando posteriormente.

Assim, imperioso identificar a problemática por trás do impasse gerado a fim de que se tenha efetividade por intermédio desse e no uso de outros mecanismos de resolução de controvérsias.

O Conselho Nacional de Justiça, inclusive, tem demonstrado deveras interesse na administração e no funcionamento da Justiça, sobretudo quando se preocupa igualmente com os mecanismos de solução de controvérsias implementados no Brasil.

Ainda, propõe conceito para conciliação por meio da Resolução $n^{\circ} 125 / 2010$, como sendo de fato "um meio alternativo de resolução de conflitos em que as partes confiam a uma terceira pessoa (neutra), o conciliador, a função de aproximá-las e orientá-las na construção de um acordo." (CONSELHO NACIONAL DE JUSTIÇA, 2010).

Referido princípio encontra-se respaldo e tem utilidade prática atualmente não somente em demandas cíveis, mas também em demandas trabalhistas e em outras demais jurisdições.

Trata-se, portanto, de instituto de extrema relevância à administração da Justiça, evoluindo-se e ganhando inclusive novas nomenclaturas, mas todas derivam dessa essência que busca a consolidação da paz. 
Além desse, tem-se a Mediação, elogiada por Humberto Theodoro Júnior (2018, v. 1, p. 76):

Em diversos países, a cultura social tem desviado grande parte dos conflitos para mecanismos extrajudiciais, como a mediação e a conciliação, que, além de aliviar a pressão sobre a Justiça Pública, se apresentam em condições de produzir resultados substancialmente mais satisfatórios do que os impostos pelos provimentos autoritários dos tribunais.

A significância do cultivo desses métodos favorece a Justiça e proporciona, sem dúvida, ao jurisdicionado qualidade efetiva de acesso à Justiça.

\section{SENTIDO PRINCIPIOLÓGICO DO TERMO COOPERAÇÃO PROCESSUAL}

O termo cooperação como se encontra no art. $6^{\circ}$ do Código de Processo Civil, no qual, nesse princípio, consta que devem cooperar entre si todos os sujeitos do processo para que, assim, se obtenha no tempo razoável a resolução da lide de forma justa.

Dessa forma, deverá cooperar entre si parte/parte e juiz/ partes, fazendo com que haja mais participação e cooperação entre estas de forma com que finalize o processo com celeridade e eficácia.

O processo vem de uma atividade triangular entre o juiz e entre as partes, que exige postura ativa de boa-fé e isonomia de ambas as partes processuais, principalmente do juiz, que age como colaborador do processo e não somente como um fiscal de regras, visando à tutela mais célere.

Desse modo, percebe-se que a grande insatisfação das partes é a insuficiência de prover a justiça a quem ele procura uma solução célere para seus problemas. 
Assim, lotados de processos e pressionados para atingirem os prazos, os juízes tentam resolver os problemas da insatisfação pela lentidão acelerando o ritmo de trabalho.

Conclui-se que fora criado o princípio da cooperação com o desafio de lançar harmonização ao ordenamento jurídico, facilitando o trabalho do julgador e ajudando a todos que se envolvem na justiça, para se ter a solução justa da lide de forma tranquila e sem prejudicar ambas as partes.

Logo, para que isso ocorra, no primeiro momento do processo, o juiz deverá buscar a autocomposição e, não obtida, deverá tentá-la em qualquer tempo do processo.

Informa-se que é função do magistrado responsável dilatar prazos processuais que não tenham se esgotado e, de certa forma, poderá ainda alterar a ordem de produção dos meios de prova, observando e adequando-os diante da necessidade do conflito.

Isso posto, o princípio em questão busca reconhecer o procedimento e o fortalecimento da argumentação favorável à teoria da relação jurídica triangular do processo como já mencionados (juiz, autor e réu).

Conforme elucida Didier Junior (2005, p 76):

Atualmente, prestigia-se no Direito estrangeiro mais precisamente na Alemanha, França e em Portugal e, já com algumas repercussões na doutrina brasileira o chamado princípio da cooperação, que orienta o magistrado a tomar uma posição de agente colaborador do processo, de participante ativo do contraditório e não mais a de um mero fiscal de regras.

Portanto, veja-se o dever de maior relevância do magistrado em questão, qual seja, o da modificação das decisões judiciais, que fez com que o magistrado, conforme o novo Código de Processo Civil, tenha a obrigação de fundamentar todas as decisões tomadas por ele. 
Assim, acata-se todo e qualquer argumento da parte, de fato ou de direito, entendendo-se relevantes ou não, de forma a demonstrar que o magistrado participou e cooperou com o processo, não prejudicando nenhuma das partes do processo.

A obediência a esse princípio é um comportamento que impede ou dificulta a decretação de nulidades processuais como também a prolação do juízo de inadmissibilidade, pois ela facilita, de todos as formas, que as partes tenham uma conciliação de forma amigável, ou até mesmo facilita ao magistrado tomar as decisões corretas.

Como afirma Freitas (2006, p. 168):

A progressiva afirmação do princípio da cooperação, considerado já uma trave mestra do processo civil moderno, leva frequentemente a falar duma comunidade de trabalho (Arbeitsgemeinschaft) entre as partes e o tribunal para a realização da função processual.

Analisando o princípio destacado anteriormente, vê-se que ele gera os 3 (três) deveres que todo o magistrado deve e tem que prestar: o de esclarecimento, o de consultar e o de prevenir.

Primeiramente, o dever de esclarecimento incide no dever de o tribunal responsável esclarecer-se junto às partes quanto às suas dúvidas, ou até mesmo quanto a alguma posição do processo para que, assim, as partes não tomem decisões equivocadas e acabem fazendo algo prejudicial.

Quanto ao dever de consultar, o juiz deve estar disposto a ouvir as partes, as questões de fato ou até mesmo as questões de direito que interferirão no julgamento da lide, pois é assim que as partes cooperarão com o processo, para que, desse modo, o magistrado consiga dar a sua devida decisão.

Por fim, o dever de prevenir nada mais é do que o apontamento do magistrado às partes acerca dos devidos problemas 
processuais para que haja o necessário saneamento desses problemas.

Conforme elenca Mitidiero (2011, p. 58-59):

Ainda, há quem caracterize a cooperação a partir das conhecidas linhas do processo dispositivo e do processo inquisitório, apontando-a também aí como resultado da superação de ambos os modelos. Portanto, seja qual for a perspectiva, é certo que a análise histórico-dogmática da tradição processual civil mostra o rastro pelo qual se formou e ganhou corpo a colaboração no nosso contexto processual. Como se pode perceber, é facílimo reconstruir seus passos pelos corredores da história.

Entretanto, a cooperação pode ser vista como um dever de todos os sujeitos ali presentes de adotar tais condutas, de acordo com o princípio da boa-fé e da lealdade, cooperando para melhor eficiência e transparência do procedimento.

Ao se observar as formas de princípio jurídico, vê-se que a colaboração é uma forma de princípio. Contudo, o juiz pode construir a norma do caso concreto a partir do princípio, pois o princípio tem maior alcance e aceitação, por isso há de se falar em cooperação como princípio.

Apesar de a Constituição Federal não se referir ao princípio da cooperação, esta se trata de um princípio implícito.

O jurista Lenio Streck aponta que a cooperação processual não é um princípio, pois não é dotada de densidade normativa, e as regras que tratam dos procedimentos não adquirem profundidade filosófica de acordo com esse standart (STRECK; MOTTA, 2012).

Assim, a partir dessa crítica, o autor Daniel Mitidiero, em resposta, afirmou que a colaboração é sim um princípio e é um modelo de processo civil (NUNES, 2008). 
O autor Dierle José Coelho Nunes (2008, p. 215) informa que a cooperação parece ser a mais adequada para uma democracia e deve ser utilizado um modelo coparticipativo de processo para a construção de um processo civil democrático para que fique de acordo com a Constituição.

Assim, a colaboração serve como um elemento para a organização do processo para alcançar uma decisão justa.

A cooperação no processo civil busca uma sociedade mais justa, livre e solidária, fundada na dignidade da pessoa humana. Assim, o contraditório é de suma importância, pois o diálogo entre as partes e o órgão jurisdicional é de grande valor.

\section{CONCLUSÃO}

O Código de Processo Civil de 2015, em seu art. $6^{\circ}$ que, de maneira inovadora, trata do princípio da cooperação para que as partes e o juiz cooperem entre si.

Desse modo, tornando um processo mais justo e com uma resolução mais rápida e eficaz, traz consigo seus demais componentes para o melhor andamento processual.

Com essa previsão legal, é notável que a justiça necessite desse princípio e dos seus seguintes para que haja, além da cooperação, mais celeridade nos campos judiciários, fazendo com que se tenha mais precisão para que o magistrado tome uma decisão mais justa para ambas as partes do processo.

O dever de cooperação está previsto no art. $6^{\circ}$ do Código de Processo Civil, que dispõe que as partes devem caminhar em sintonia com o mesmo objetivo para que o processo seja finalizado em tempo razoável e com eficácia jurisdicional.

Dentro desse conjunto normativo, inclusive, extrai-se diversos princípios e novas teorias a serem aplicados para melhor funcionamento da Justiça. 
Note-se que a preocupação do legislador fora justamente trazer, nesse Diploma legal, medidas para solucionar presentes e futuros impasses no que tange ao alto número de litígios catalogados em todo o Brasil.

Fora pontuado a utilidade dos mecanismos de resolução de controvérsias com enfoque na conciliação, a qual norteia igualmente o Código de Processo Civil, além de outros, a exemplo da não surpresa processual, da paridade de armas, fundamentados, principalmente, no livre acesso a uma efetiva Justiça.

Na cooperação que se torna o núcleo da abordagem, sobretudo, as partes e o juiz devem se unir para propiciar um processo bem conduzido, sem nulidades, com eficiência e com resultado.

Não significa renunciar direitos em prol do outro, mas sim auxiliar para que o melhor direito seja predominante. Desse modo, a cooperação também é um elemento para auxiliar na igualdade de tratamento das partes e do juiz.

\section{REFERÊNCIAS}

BRASIL. Lei no 13.105, de 16 de março de 2015. Código de Processo Civil. Brasília, DF: Presidência da República, 2015b. Disponível em: http://www.planalto.gov.br/ccivil_03/_Ato20152018/2015/Lei/ L13105.htm \#art1045. Acesso em: 3 jan. 2019.

CONSELHO NACIONAL DE JUSTIÇA (Brasil). Resolução n. 125, de 29 de novembro de 2010. Brasília, DF: CNJ, 2010. Disponível em: http://www.cnj.jus.br/busca-atos-adm?documento $=2579$. Acesso em: 29 jan. 2020.

DIDIER JUNIOR, Fredie. O princípio da cooperação: uma apresentação. Revista de Processo, São Paulo, v. 127, p. 75-80, 2005.

DONIZETTI, Elpidio. Curso de direito processual civil. 6 . ed. São Paulo: Atlas, 2010.

FREITAS, José Lebre de. Introdução ao processo civil: conceito e princípios gerais. 2. ed. Coimbra: Coimbra Editora, 2006. 
GONÇALVES, Marcus Vinicius Rios. Direito processual civil esquematizado. 7. ed. São Paulo: Saraiva, 2016.

GUERRA, Marcelo Lima. Direitos fundamentais e a proteção do credor na execução civil. São Paulo: Revista dos Tribunais, 2003.

LIMA, Leandro Rigueira Rennó. Arbitragem: uma análise da fase pré-arbitral. Belo Horizonte: Mandamentos, 2003.

MITIDIERO, Daniel Francisco. Colaboração no processo civil como prêt-à-porter? Um convite ao diálogo para Lenio Streck. Revista de processo, São Paulo, v. 36, n. 194, abr. 2011.

MORAES, Alexandre de. Constituição do Brasil interpretada. 6. ed. São Paulo: Atlas, 2006.

NUNES, Dierle José Coelho. Processo jurisdicional democrático. Curitiba: Juruá, 2008.

SILVA, José Afonso. Curso de direito constitucional positivo. 25. ed. São Paulo: Malheiros, 2005.

STRECK, Lenio Luiz; MOTTA, Francisco José Borges. Um debate com (e sobre) o formalismo-valorativo de Daniel Mitidiero, ou: "Colaboração no processo civil" é um princípio? Revista de Processo, São Paulo, v. 37, n. 213. 2012.

TARTUCE, Fernanda. Mediação de conflitos: proposta de emenda constitucional e tentativas consensuais prévias à jurisdição. Revista Magister de Direito Civil e Processual Civil, ed. 82, p. 5-21, jan./fev. 2018.

THEODORO JÚNIOR, Humberto. Curso de direito processual civil. 59. ed. rev., atual e ampl. Rio de Janeiro: Forense, 2018. v. 1.

WARAT, Luís Alberto. O ofício do mediador. Florianópolis: Habitus, 2001.

Recebido em: 16/03/2020

Aprovado em: 03/08/2020 